\title{
The effect of neighborhood disadvantage on the racial disparity in ovarian cancer-specific survival in a large hospital-based study in Cook County, Illinois
}

\author{
Caryn E. Peterson ${ }^{1}$, Garth H. Rauscher ${ }^{1}$, Timothy P. Johnson ${ }^{2}$, Carolyn V. Kirschner ${ }^{3,4}$, Sally Freels ${ }^{1}$ \\ Richard E. Barrett ${ }^{5}$, Seijeoung Kim ${ }^{6}$, Marian L. Fitzgibbon ${ }^{7}$, Charlotte E. Joslin ${ }^{8}$ and Faith G. Davis ${ }^{1,9 *}$ \\ 1 Division of Epidemiology and Biostatistics (MC 923), School of Public Health, University of Illinois at Chicago, Chicago, IL, USA \\ ${ }^{2}$ Survey Research Laboratory, Public Administration, University of Illinois at Chicago, Chicago, IL, USA \\ ${ }^{3}$ Division of Gynecologic Oncology, NorthShore University HealthSystem, Evanston, IL, USA \\ ${ }^{4}$ Department of Obstetrics and Gynecology, University of Chicago, Chicago, IL, USA \\ ${ }^{5}$ Center for Health Behavior Research, University of Illinois at Chicago, Chicago, IL, USA \\ ${ }^{6}$ Division of Health Policy and Administration, School of Public Health, University of Illinois at Chicago, Chicago, IL, USA \\ ${ }^{7}$ Department of Medicine, School of Public Health, University of Illinois at Chicago, Chicago, IL, USA \\ ${ }^{8}$ Department of Ophthalmology and Visual Sciences, University of Illinois at Chicago, Chicago, IL, USA \\ ${ }^{9}$ School of Public Health, University of Alberta, Edmonton, AB, Canada
}

Edited by:

Onyebuchi A. Arah, University of California Los Angeles, USA

Reviewed by:

Preethi S. Raj, National Institutes of Health, USA

Caroline A. Thompson, Palo Alto

Medical Foundation Research

Institute, USA

*Correspondence:

Faith G. Davis, School of Public Health, University of Alberta, 3-317

Edmonton Clinic Health Academy,

1140587 Avenue, Edmonton, AB T6G

1C9, Canada

e-mail: faith.davis@ualberta.ca
This paper examines the effect of neighborhood disadvantage on racial disparities in ovarian cancer-specific survival. Despite treatment advances for ovarian cancer, survival remains shorter for African-American compared to White women. Neighborhood disadvantage is implicated in racial disparities across a variety of health outcomes and may contribute to racial disparities in ovarian cancer-specific survival. Data were obtained from 581 women (100 African-American and 481 White) diagnosed with epithelial ovarian cancer between June 1, 1994, and December 31, 1998 in Cook County, IL, USA, which includes the city of Chicago. Neighborhood disadvantage score at the time of diagnosis was calculated for each woman based on Browning and Cagney's index of concentrated disadvantage. Cox proportional hazard models measured the association of self-identified African-American race with ovarian cancer-specific survival after adjusting for age, tumor characteristics, surgical debulking, and neighborhood disadvantage. There was a statistically significant negative association $(-0.645)$ between ovarian cancer-specific survival and neighborhood disadvantage $(p=0.008)$. After adjusting for age and tumor characteristics, African-American women were more likely than Whites to die of ovarian cancer $(H R=1.59, p=0.003)$. After accounting for neighborhood disadvantage, this risk was attenuated $(H R=1.32, p=0.10)$. These findings demonstrate that neighborhood disadvantage is associated with ovarian cancer-specific survival and may contribute to the racial disparity in survival.

Keywords: ovarian cancer and socioeconomic status, survival analysis, healthcare disparities, neighborhood effect, racial disparities in ovarian cancer

\section{INTRODUCTION}

Ovarian cancer is the fifth leading cause of cancer death among U.S. women, with an estimated 21,980 new cases diagnosed in 2014 and 14,270 deaths (1). Across study populations, the incidence of ovarian cancer has been consistently higher in White women than in African-American women (2-4). Paradoxically, African-Americans have been consistently found to have poorer survival than Whites at all stages of this disease (5-7). Recent SEER data show improvements in the 5 -year relative survival for women diagnosed with ovarian cancer, yet these rates remain significantly lower for African-American women compared to Whites (36 and $44 \%$, respectively) (1).

Racial disparities in cancer survival are typically assessed solely in terms of individual-level factors, and rightly so. Racial differences in individual-level demographic and clinical factors play an important role in prolonging or shortening survival following diagnosis of various types of cancer (8-10). Yet, these individuallevel differences may be due in part to differences in neighborhood environments, and excluding this important contextual factor may produce an incomplete picture. This analysis explores the role that neighborhood, and in particular neighborhood disadvantage, plays in explaining the racial disparity in ovarian cancer survival.

Sampson and colleagues $(11,12)$ have defined neighborhoods as "ecological units nested within successively larger communities." Implicit in this definition is the concept of neighborhood differentiation, which includes aspects such as social inequality between neighborhoods and the idea that neighborhood characteristics can influence aspects of residents' lives. One aspect of social inequality at the neighborhood level is residential segregation. Massey and Denton (13) describe the damaging social consequences of residential segregation, which include social and economic isolation as well as structural environments 
characterized by physical decay, crime, and social disorder. Ellen and colleagues (14) propose several pathways by which neighborhoods can affect health. For example, weak neighborhood resources can reduce access to and quality of healthcare, and physical stresses in a neighborhood can pose challenges to health-promoting behaviors such as physical activity and healthy eating.

Neighborhood disadvantage has been implicated in racial disparities across a variety of health outcomes (15-17) above and beyond individual-level demographic, socioeconomic, and clinical factors (18-20), and differences in neighborhood disadvantage may also contribute to disparities in ovarian cancer-specific survival. Sampson and colleagues (12) suggest several ways in which the effect of neighborhood disadvantage may be particularly strong for African-Americans. These include the connection between concentrated disadvantage and residential isolation, as well as the "bundling" of social problems that occur at the neighborhood level, such as weak bonds of social support, economic uncertainty, and both social and physical disorder. Residence in high-poverty neighborhoods has been associated with shorter survival in individuals diagnosed with breast cancer $(21,22)$, prostate cancer (23), and lung cancer (24), and this may also be the case for women with ovarian cancer.

Using Browning and Cagney's (25) index of concentrated disadvantage, we examined whether neighborhood disadvantage was associated with cancer-specific survival, and whether this association helped to explain any observed survival disparity among African-American and White women diagnosed with ovarian cancer in Cook County, IL, USA, which includes the city of Chicago.

\section{MATERIALS AND METHODS STUDY POPULATION}

Cases from an original case-control study examining the etiology of ovarian cancer were recruited from hospitals in Cook County, IL, USA between June 1, 1994, and December 31, 1998. Eightythree percent of hospitals in Cook County participated in the study. These hospitals represent a wide array of community hospitals in the Chicago metropolitan area, including major teaching hospitals, county hospitals, and system affiliated hospitals in a range of sizes. Identified cases were subsequently sent to the Illinois State Cancer Registry (ISCR) to determine whether any eligible cases had been missed. Of the 1,562 identified by ISCR during the ascertainment period, 1,210 (77.5\%) were part of the original case-control study. The remaining 352 ISCR cases were excluded for the following reasons: cases could not be reviewed for eligibility because they were diagnosed in a non-participating hospital $(n=130)$, the medical record could not be obtained $(n=75)$, the case was identified through death certificate $(n=35)$, and the case did not meet the study's age or race eligibility criteria $(n=112)$. Diagnosis was confirmed after surgical biopsy using the International Histological Classification of Ovarian Tumors recommended by the Féderation Internationàle de Gynécologie et d'Obstétrique (FIGO) (26). A pathology review of 386 of the eligible cases was conducted by an independent gynecologic pathologist. Hospital pathology reports were used for histologic classification for the remaining cases.
Cases of epithelial ovarian cancer ("ovarian cancer") were eligible for inclusion in this analysis if they were residents of Cook County, treated at one of the participating hospitals, $18-74$ years old at the time of diagnosis, and self-reported their race as either "Black" or "White." Among the 1,210 cases available between June 1, 1994 and December 31, 1998, 702 met the eligibility criteria. After reviewing histology codes, 102 tumors were determined to be either benign, stromal, or of germ-cell origin, and were subsequently excluded from this analysis. Of the remaining 600 cases, vital status was valid for 581 women. The protocol was approved by the University of Illinois at Chicago Institutional Review Board.

\section{VITAL STATUS}

Case information was submitted to the National Death Index (NDI) and matched through December 2008. Vital status was determined through a manual review of the NDI Summary file, with dates of death recorded for all linked cases. In cases with more than one possible match, the record with the most data items in agreement was used. Unlinked cases were right-censored at the last date of December 31, 2008. The cause of death was classified as either ovarian cancer or ovarian cancer-related death using the underlying and selected-cause codes from the appropriate revision of the International Classification of Diseases (ICD-9, -10). The study endpoint was ovarian cancer-specific survival time calculated by subtracting the date of ovarian cancer diagnosis from the date of death due to ovarian cancer or censoring at the last date of December 31, 2008.

\section{VARIABLES}

A composite variable representing neighborhood disadvantage was constructed using U.S. Census data and was based on Browning and Cagney's concentrated disadvantage factor, which was dominated by high factor loadings for percent below the poverty line, unemployed, in female-headed households, under age 18 , and African-American (25). Because the case-ascertainment period (i.e., 1994-1998) spanned two U.S. Census periods, both the 1990 and 2000 census periods were used to develop the variable. Each patient's residential address at the time of diagnosis was geocoded to the block level and then located within a census tract. Data from the 1990 and 2000 Census periods were used to create interpolated values representing the midpoint in the ascertainment period (i.e., 1996) for each of the following census variables: percent below poverty, percent unemployed, percent receiving public assistance, percent in female-headed households, percent under age 18, and percent African-American. Each interpolated value was standardized (i.e., converted to $z$-scores). The variables were then summed with equal weighting and standardized to create the final disadvantage index variable. Higher scores represented greater concentrated disadvantage.

Stage at diagnosis was analyzed as late-stage (FIGO III/IV) versus early-stage (FIGO I/II) diagnosis. The pathologic grade of tumors was classified as high pathologic grade (moderately to poorly differentiated) versus low grade (well differentiated). The FIGO version of the World Health Organization's histologic typology of ovarian tumors was used to classify the six categories of epithelial tumors: serous, mucinous, clear cell, endometrioid, undifferentiated, and unclassified. (Tumors were considered 
unclassified if they could not be assigned to any of the other five groups or if they had no histology.) Epithelial histologic sub-type was analyzed as serous versus all others due to small cell sizes in the non-serous sub-types. Finally, tumors were considered suboptimally debulked following initial surgery when residual lesions were $>2 \mathrm{~cm}$ (the definition at the time cases were diagnosed), and considered optimally debulked when lesions were $2 \mathrm{~cm}$ or less. Only epithelial tumors were included in this analysis.

\section{STATISTICAL ANALYSIS}

Differences in the distribution of tumor characteristics by race and quartile of disadvantage were tested using Chi-square and $t$-test statistics for categorical and continuous variables, respectively. Simple linear regression was used to evaluate the association between cancer-specific survival time and disadvantage. The Cochran-Armitage test was used to evaluate the linear trend of variables by quartile of disadvantage. Unadjusted Kaplan-Meier 5- and 10-year survival rates and 95\% confidence intervals were estimated for African-American and White women.

Three Cox proportional hazard $(\mathrm{PH})$ models measured the association of race (African-American) with ovarian cancerspecific survival time: Model 1 estimated the age-adjusted hazard of death by race; Model 2 estimated the hazard of death by race controlling for age, tumor characteristics, and surgical debulking; Model 3 estimated the hazard of death by race controlling for age, tumor characteristics, surgical debulking, and neighborhood disadvantage (comparing the highest quartile of disadvantage to the lower three quartiles as the reference category). Product terms tested the interaction between race and disadvantage. No violations of the PHs assumption were observed ( $p$ values for interaction with time ranged from 0.45 to 0.88 ). Similar Cox models were run with the shared frailty model to account for clustered data (i.e., cases within census tracts.) Analyses were performed using SAS (v9.3, Cary, NC, USA).

\section{RESULTS}

By the end of the follow-up period, 87 of 100 (87\%) AfricanAmericans versus 358 of 481 (74\%) Whites had died $(p=0.007)$. The mean survival time for African-Americans was 16.9 months shorter than for Whites (61.5 versus 78.4 months, $p=0.007)$. There was a statistically significant negative association $(-0.645)$ between ovarian cancer-specific survival and neighborhood disadvantage ( $p=0.008$ ) (Results not shown).

Table 1 presents the distribution and association of patient characteristics by race and quartile of disadvantage. Median survival was 3.18 years for African-Americans versus 5.31 years for

Table 1 | Percent distribution and association of patient characteristics, by race and quartile ${ }^{a}$ of disadvantage $(n=581)$.

\begin{tabular}{|c|c|c|c|c|c|c|c|c|}
\hline & \multicolumn{3}{|c|}{ Race } & \multicolumn{5}{|c|}{ By quartile of disadvantage score } \\
\hline & African-Americans & Whites & $\boldsymbol{p}$ & 1st & 2nd & 3rd & 4th & $p_{\text {Trend }}$ \\
\hline & $n=100(\%)$ & $n=481(\%)$ & & $n=146(\%)$ & $n=145(\%)$ & $n=145(\%)$ & $n=145(\%)$ & \\
\hline Mean survival in years & 5.12 & 6.54 & 0.007 & 6.55 & 6.82 & 6.45 & 5.35 & 0.46 \\
\hline (SD) & $(-0.45)$ & $(-0.2)$ & & $(-4.8)$ & $(-4.8)$ & $(-4.7)$ & $(-4.7)$ & \\
\hline [Median] & [3.18] & {$[5.31]$} & & {$[5.27]$} & {$[5.61]$} & {$[5.30]$} & {$[2.99]$} & \\
\hline \multicolumn{9}{|l|}{ FIGO stage at diagnosis } \\
\hline Early (FIGO I/II) & $42(42)$ & $224(46.6)$ & 0.40 & $75(51.4)$ & $64(44.1)$ & $69(47.6)$ & $58(40)$ & 0.09 \\
\hline Late (FIGO III/IV) & $58(58)$ & $257(53.4)$ & & $71(48.6)$ & $81(55.9)$ & $76(52.4)$ & $87(60)$ & \\
\hline \multicolumn{9}{|l|}{ Pathologic grade } \\
\hline Low-grade & $26(26)$ & $150(31.2)$ & 0.30 & $48(32.9)$ & $49(33.8)$ & $48(33.1)$ & $31(21.4)$ & 0.04 \\
\hline High-grade & $74(74)$ & $331(68.8)$ & & $98(67.1)$ & $96(66.2)$ & 97 (66.9) & $114(78.6)$ & \\
\hline \multicolumn{9}{|l|}{ Histologic sub-type } \\
\hline Serous & $53(53)$ & $230(47.8)$ & 0.35 & $67(45.9)$ & $71(49)$ & $73(50.3)$ & $72(49.7)$ & 0.49 \\
\hline All others & $47(47)$ & $251(52.2)$ & & $79(54.1)$ & $74(51)$ & $72(49.7)$ & $73(50.3)$ & \\
\hline \multicolumn{9}{|c|}{ Surgical debulking (missing $=25$ ) } \\
\hline Optimal debulking & $45(51.7)$ & $278(59.3)$ & 0.19 & $92(63.9)$ & $82(59)$ & $82(58.2)$ & $67(50.8)$ & 0.03 \\
\hline Suboptimal debulking & $42(48.3)$ & $191(40.7)$ & & $52(36.1)$ & $57(41)$ & $59(41.8)$ & $65(49.2)$ & \\
\hline Mean disadvantage score ${ }^{b}$ & 0.79 & -0.65 & $<0.0001$ & & & & & \\
\hline (SD) & $(0.84)$ & $(0.34)$ & & & & & & \\
\hline [Range] & {$[-0.93,2.33]$} & {$[-1.06,1.71]$} & & & & & & \\
\hline \multicolumn{9}{|l|}{ Quartile of disadvantage } \\
\hline Highest (4th Q) & $85(85)$ & $60(12)$ & $<0.0001$ & & & & & \\
\hline 1st-3rd Quartiles & $15(15)$ & $421(88)$ & & & & & & \\
\hline
\end{tabular}

${ }^{a}$ Neighborhood disadvantage divided into fourths at the quartiles of the sample distribution.

${ }^{b}$ Higher scores reflect greater concentrated disadvantage. 
Whites $(p=0.007)$. There were no statistically significant differences in tumor characteristics between the two groups of women. African-American women in the study lived in neighborhoods with significantly higher mean disadvantage scores compared to White women $(0.79$ versus $-0.65, p<0.0001)$, and the majority of African-Americans lived in neighborhoods in the highest quartile of disadvantage $(85 \%)$, compared to $12 \%$ of Whites $(p<0.0001)$.

The highest quartile of neighborhood disadvantage was associated with late-stage diagnosis $(p=0.05)$, high-grade tumors $(p=0.03)$, suboptimal debulking $(p=0.03)$, and race $(p<0.0001)$. The likelihood of being diagnosed with higher grade tumors and receiving suboptimal debulking was also associated with increasing quartile of disadvantage, and was marginally associated with late-stage diagnosis $(p=0.04, p=0.03$, and $p=0.09$, respectively). Because the strongest effect of disadvantage was observed in the highest quartile, this variable was evaluated as a binary variable in the subsequent series of Cox models.

Table 2 | Kaplan-Meier ovarian cancer-specific survival rates (95\% Cl), by race $(n=581)$.

\begin{tabular}{|c|c|c|}
\hline & \multicolumn{2}{|c|}{ Survival rate $(95 \% \mathrm{CI})$} \\
\hline & 5-year & 10-year \\
\hline African-Americans & $0.41(0.31,0.51)$ & $0.24(0.16,0.33)$ \\
\hline Whites & $0.62(0.57,0.66)$ & $0.43(0.39,0.48)$ \\
\hline
\end{tabular}

The unadjusted Kaplan-Meier 5-year cancer-specific survival rates for African-Americans and Whites were 41 and $62 \%$, respectively, and 24 and 43\%, respectively, for 10-year survival (Table 2).

The results of age-adjusted Cox $\mathrm{PH}$ models estimating the association between race (African-American) and ovarian cancerspecific mortality are presented in Table 3. African-American women were more likely than White women to die of ovarian cancer (Model $1: \mathrm{HR}=1.54, p=0.004$ ). This increased risk held after adjusting for tumor characteristics (Model 2: $H R=1.59$, $p=0.003)$. However, after accounting for neighborhood disadvantage, this risk was attenuated (Model 3: $\mathrm{HR}=1.32, p=0.10$ ). There was no statistically significant interaction between race and disadvantage, and a model accounting for clustered data produced nearly identical results to the Table 3 model ignoring clustering (data not shown).

\section{DISCUSSION}

Our findings are consistent with similar analyses examining the effect of neighborhood environment on survival in residents with breast (27), prostate (23), and lung cancer (24). To our knowledge there are no published reports examining the effect of neighborhood disadvantage (or neighborhood-level socioeconomic status) on racial disparities in ovarian cancer-specific survival. However, at the individual-level, lower socioeconomic status has been associated with poorer survival in women diagnosed with invasive ovarian cancer (28-30).

Table 3 | Hazard ratios (HR) for African-American versus White ovarian cancer-specific mortality

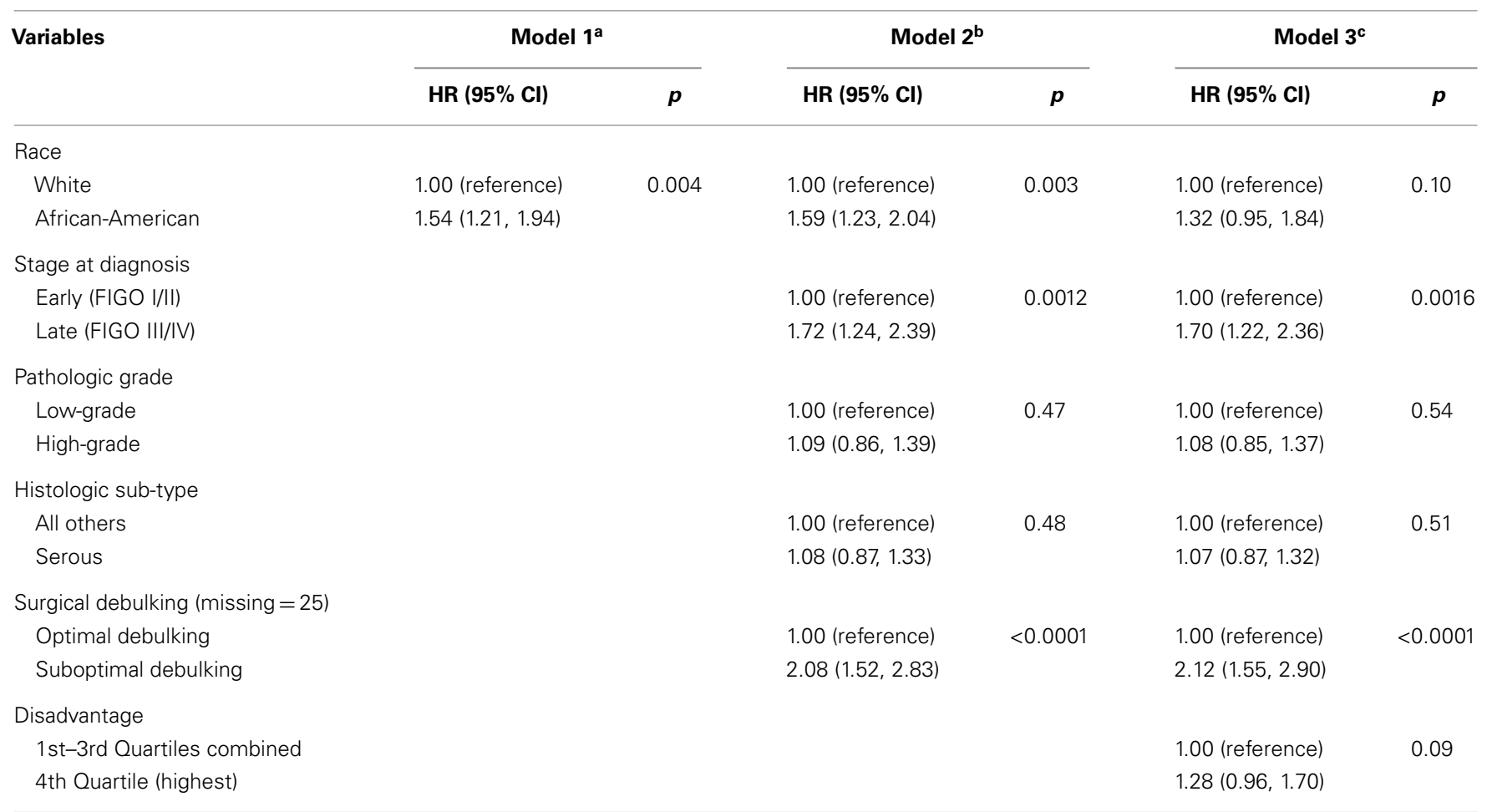

${ }^{a}$ Adjusted for age at diagnosis.

${ }^{b}$ Adjusted for age, stage at diagnosis, pathologic grade, histologic sub-type, and surgical debulking.

${ }^{c}$ Adjusted for age, stage at diagnosis, pathologic grade, histologic sub-type, surgical debulking, and concentrated disadvantage. 
This study shows that neighborhood disadvantage is associated with ovarian cancer-specific survival and may contribute to the racial disparity in such survival. Although the pathways through which neighborhood disadvantage influences survival are challenging to measure, we hypothesize several causal relations between indicators of neighborhood disadvantage and ovarian cancer-specific survival. Neighborhood disadvantage adversely affects both individual- and neighborhood-level socioeconomic status, as well as the physical and structural environment of the community (31). At the individual level, poverty may affect survival through higher rates of comorbidities (32), which may influence both physicians' recommendations and women's abilities to receive and complete treatment for advanced ovarian cancer $(33,34)$. Poverty and unemployment are associated with inadequate health insurance $(32,35)$, which impacts the quality of available healthcare (36-40) in terms of treatment (41) as well as management of treatment and disease complications (42).

In addition, neighborhood socioeconomic status is an important contextual factor that negatively impacts health outcomes beyond an individual's own circumstances $(43,44)$. An environment of high poverty, high unemployment, and low educational attainment can produce conditions in which priorities such as personal safety, maintaining employment, and caring for one's family take precedence over health (45-47). These competing priorities can result in later-stage diagnosis and can make treatment completion difficult $(48,49)$.

Finally, neighborhoods of high concentrated disadvantage expose residents to environmental stressors including crime, neighborhood disorder and decay, and discrimination (50,51). These environmental stressors may place residents at risk for high levels of stress and distress $(52,53)$, both of which have an adverse effect on immune processes involved in cancer progression (54) and may increase the likelihood of advanced ovarian cancer $(55,56)$. For all of these reasons, living in a neighborhood with increased concentrated disadvantage adds an "additional layer of vulnerability" over and above an individual's personal circumstances (57).

Although this study provides useful insights into the possible causes of racial disparity in ovarian cancer-specific survival between African-American and White women, we acknowledge important limitations which should be addressed in future research. First, direct measures of healthcare access and utilization were not included in this study, and they should be examined in order to assess their possible contribution to disparate survival. Second, the length of residency within a census tract was not known, so models could not account for potential changes in residency after diagnosis. Third, the impacts of prescribed treatment and patients' responses to that treatment on the survival disparity were not measured. Research has shown that African-Americans are less likely to receive the type of optimal treatment associated with longer survival (29, $58,59)$. It is possible that the African-American women in our study may have received less optimal treatment than Whites in terms of cytoreductive surgery or chemotherapeutic regimen, or both, possibly due to differences in healthcare providers or comorbidities that prevented the use of certain therapies (60). Finally, cases were among women diagnosed with ovarian cancer exclusively in Cook County, IL, USA and from a subset of hospitals within the county, which may not be representative of the general population of ovarian cancer patients in the U.S., particularly with respect to stage at diagnosis or receipt of surgical treatment.

This analysis demonstrates that neighborhood disadvantage is an independent predictor of ovarian cancer-specific survival and may contribute to the racial disparity in survival. This association is most evident in the highest quartile of concentrated disadvantage, suggesting a gradient effect (61) of neighborhood disadvantage on racially disparate survival. Future studies of the racial disparity in ovarian cancer-specific survival should also examine the role of neighborhood disadvantage, accounting for racial differences in treatment.

\section{ACKNOWLEDGMENTS}

This research was funded by the NIH-NIMHD Training Program: Center of Excellence in Elimination Disparities (P60MD003424).

\section{REFERENCES}

1. Siegel R, Ma J, Zou Z, Jemal A. Cancer statistics, 2014. CA Cancer J Clin (2014) 64(1):9-29. doi:10.3322/caac.21208

2. Goodman MT, Shvetsov YB. Incidence of ovarian, peritoneal, and fallopian tube carcinomas in the United States, 1995-2004. Cancer Epidemiol Biomarkers Prev (2009) 18(1):132-9. doi:10.1158/1055-9965.EPI-08-0771

3. Goodman MT, Howe HL, Tung KH, Hotes J, Miller BA, Coughlin SS, et al. Incidence of ovarian cancer by race and ethnicity in the United States, 1992-1997. Cancer (2003) 97(10 Suppl):2676-85. doi:10.1002/cncr.11349

4. Collins Y, Holcomb K, Chapman-Davis E, Khabele D, Farley JH. Gynecologic cancer disparities: a report from the health disparities taskforce of the society of gynecologic oncology. Gynecol Oncol (2014) 133(2):353-61. doi:10.1016/j.ygyno.2013.12.039

5. Terplan M, Schluterman N, McNamara EJ, Tracy JK, Temkin SM. Have racial disparities in ovarian cancer increased over time? An analysis of SEER data. Gynecol Oncol (2012) 125(1):19-24. doi:10.1016/j.ygyno.2011.11.025

6. Albain KS, Unger JM, Crowley JJ, Coltman CA Jr, Hershman DL. Racial disparities in cancer survival among randomized clinical trials patients of the Southwest Oncology Group. J Natl Cancer Inst (2009) 101(14):984-92. doi:10.1093/jnci/djp175

7. Kim S, Dolecek TA, Davis FG. Racial differences in stage at diagnosis and survival from epithelial ovarian cancer: a fundamental cause of disease approach. Soc Sci Med (2010) 71(2):274-81. doi:10.1016/j.socscimed.2010.03.033

8. Wu AH, Gomez SL, Vigen C, Kwan ML, Keegan TH, Lu Y, et al. The California breast cancer survivorship consortium (CBCSC): prognostic factors associated with racial/ethnic differences in breast cancer survival. Cancer Causes Control (2013) 24(10):1821-36. doi:10.1007/s10552-013-0260-7

9. Long B, Liu FW, Bristow RE. Disparities in uterine cancer epidemiology, treatment, and survival among African Americans in the United States. Gynecol Oncol (2013) 130(3):652-9. doi:10.1016/j.ygyno.2013.05.020

10. Adams SA, Butler WM, Fulton J, Heiney SP, Williams EM, Delage AF, et al. Racial disparities in breast cancer mortality in a multiethnic cohort in the Southeast. Cancer (2012) 118(10):2693-9. doi:10.1002/cncr.26570

11. Sampson RJ. The neighborhood context of well-being. Perspect Biol Med (2003) 46(3 Suppl):S53-64. doi:10.1353/pbm.2003.0073

12. Sampson RJ, Morenoff JD, Gannon-Rowley T. Assessing "neighborhood effects": social processes and new directions in research. Annu Rev Sociol (2002) 28:443-78. doi:10.1146/annurev.soc.28.110601.141114

13. Massey DS, Denton NA. American Apartheid: Segregation and the Making of the Underclass. Cambridge, MA: Harvard University Press (1993).

14. Ellen IG, Mijanovich T, Dillman K-N. Neighborhood effects on health: exploring the links and assessing the evidence. J Urban Aff (2001) 23(3-4):391-408. doi:10.1111/0735-2166.00096

15. Reagan PB, Salsberry PJ. Race and ethnic differences in determinants of preterm birth in the USA: broadening the social context. Soc Sci Med (2005) 60(10):2217-28. doi:10.1016/j.socscimed.2004.10.010 
16. Acevedo-Garcia D. Residential segregation and the epidemiology of infectious diseases. Soc Sci Med (2000) 51(8):1143-61. doi:10.1016/S0277-9536(00) 00016-2

17. Browning CR, Cagney KA, Wen M. Explaining variation in health status across space and time: implications for racial and ethnic disparities in selfrated health. Soc Sci Med (2003) 57(7):1221-35. doi:10.1016/S0277-9536(02) 00502-6

18. Warner ET, Gomez SL. Impact of neighborhood racial composition and metropolitan residential segregation on disparities in breast cancer stage at diagnosis and survival between black and white women in California. J Community Health (2010) 35(4):398-408. doi:10.1007/s10900-010-9265-2

19. Osypuk TL. Future research directions for understanding neighborhood contributions to health disparities. Rev Epidemiol Sante Publique (2013) 61(Suppl 2):S61-8. doi:10.1016/j.respe.2013.03.040

20. Johnson RC, Schoeni RF, Rogowski JA. Health disparities in mid-to-late life: the role of earlier life family and neighborhood socioeconomic conditions. Soc Sci Med (2012) 74(4):625-36. doi:10.1016/j.socscimed.2011.10.021

21. Harper S, Lynch J, Meersman SC, Breen N, Davis WW, Reichman MC. Trends in area-socioeconomic and race-ethnic disparities in breast cancer incidence, stage at diagnosis, screening, mortality, and survival among women ages 50 years and over (1987-2005). Cancer Epidemiol Biomarkers Prev (2009) 18(1):121-31. doi:10.1158/1055-9965.EPI-08-0679

22. Byers TE, Wolf HJ, Bauer KR, Bolick-Aldrich S, Chen VW, Finch JL, et al. The impact of socioeconomic status on survival after cancer in the United States: findings from the National Program of Cancer Registries Patterns of Care Study. Cancer (2008) 113(3):582-91. doi:10.1002/cncr.23567

23. Freeman VL, Ricardo AC, Campbell RT, Barrett RE, Warnecke RB. Association of census tract-level socioeconomic status with disparities in prostate cancerspecific survival. Cancer Epidemiol Biomarkers Prev (2011) 20(10):2150-9. doi:10.1158/1055-9965.EPI-11-0344

24. Johnson AM, Hines RB, Johnson JA III, Bayakly AR. Treatment and survival disparities in lung cancer: the effect of social environment and place of residence. Lung Cancer (2014) 83(3):401-7. doi:10.1016/j.lungcan.2014.01.008

25. Browning CR, Cagney KA. Neighborhood structural disadvantage, collective efficacy, and self-rated physical health in an urban setting. J Health Soc Behav (2002) 43(4):383-99. doi:10.2307/3090233

26. Pecorelli S, Benedet JL, Creasman WT, Shepherd JH. FIGO staging of gynecologic cancer. 1994-1997 FIGO committee on gynecologic oncology. International federation of gynecology and obstetrics. Int J Gynaecol Obstet (1999) 65(3):243-9. doi:10.1016/S0020-7292(99)00070-3

27. Kish JK, Yu M, Percy-Laurry A, Altekruse SF. Racial and ethnic disparities in cancer survival by neighborhood socioeconomic status in surveillance, epidemiology, and end results (SEER) registries. J Natl Cancer Inst Monogr (2014) 2014(49):236-43. doi:10.1093/jncimonographs/lgu020

28. Anuradha S, Webb PM, Blomfield P, Brand AH, Friedlander M, Leung Y, et al. Survival of Australian women with invasive epithelial ovarian cancer: a population-based study. Med J Aust (2014) 201(5):283-8. doi:10.5694/mjal4. 00132

29. Bristow RE, Powell MA, Al-Hammadi N, Chen L, Miller JP, Roland PY, et al. Disparities in ovarian cancer care quality and survival according to race and socioeconomic status. J Natl Cancer Inst (2013) 105(11):823-32. doi:10.1093/jnci/djt065

30. Long B, Chang J, Ziogas A, Tewari KS, Anton-Culver H, Bristow RE. Impact of race, socioeconomic status, and the health care system on the treatment of advanced-stage ovarian cancer in California. Am J Obstet Gynecol (2014). doi:10.1016/j.ajog.2014.10.1104

31. Echeverria SE, Borrell LN, Brown D, Rhoads G. A local area analysis of racial, ethnic, and neighborhood disparities in breast cancer staging. Cancer Epidemiol Biomarkers Prev (2009) 18(11):3024-9. doi:10.1158/1055-9965.EPI-09-0390

32. Gerend MA, Pai M. Social determinants of black-white disparities in breast cancer mortality: a review. Cancer Epidemiol Biomarkers Prev (2008) 17(11):2913-23. doi:10.1158/1055-9965.EPI-07-0633

33. Tammemagi CM. Racial/ethnic disparities in breast and gynecologic cancer treatment and outcomes. Curr Opin Obstet Gynecol (2007) 19(1):31-6. doi:10.1097/GCO.0b013e3280117cf8

34. Tammemagi CM, Nerenz D, Neslund-Dudas C, Feldkamp C, Nathanson D. Comorbidity and survival disparities among black and white patients with breast cancer. JAMA (2005) 294(14):1765-72. doi:10.1001/jama.294.14.1765
35. Kirby JB, Kaneda T. Neighborhood socioeconomic disadvantage and access to health care. J Health Soc Behav (2005) 46(1):15-31. doi:10.1177/ 002214650504600103

36. Andersen RM, Davidson PL. Improving access to care in America. In: Ronald M, Anderson THR, Kominski Gerald F, editors. Individual and Contextual Indicators. San Francisco, CA: Josey-Bass (2001). p. 3-30.

37. O'Malley AS, Forrest CB. Beyond the examination room: primary care performance and the patient-physician relationship for low-income women. J Gen Intern Med (2002) 17(1):66-74. doi:10.1046/j.1525-1497.2002.10338.x

38. O’Malley AS, Forrest CB, Mandelblatt J. Adherence of low-income women to cancer screening recommendations. J Gen Intern Med (2002) 17(2):144-54. doi:10.1046/j.1525-1497.2002.10431.x

39. Berk ML, Schur CL, Cantor JC. Ability to obtain health care: recent estimates from the Robert Wood Johnson foundation national access to care survey. Health Aff (Millwood) (1995) 14(3):139-46. doi:10.1377/hlthaff.14.3.139

40. Gornick ME. A decade of research on disparities in Medicare utilization: lessons for the health and health care of vulnerable men. Am J Public Health (2008) 98(9 Suppl):S162-8. doi:10.2105/AJPH.98.Supplement_1.S162

41. Bradley CJ, Given CW, Roberts C. Race, socioeconomic status, and breast cancer treatment and survival. J Natl Cancer Inst (2002) 94(7):490-6. doi:10.1093/jnci/ 94.16.1254-a

42. Probst JC, Bellinger JD, Walsemann KM, Hardin J, Glover SH. Higher risk of death in rural blacks and whites than urbanites is related to lower incomes, education, and health coverage. Health Aff (Millwood) (2011) 30(10):1872-9. doi:10.1377/hlthaff.2011.0668

43. Diez-Roux AV, Nieto FJ, Muntaner C, Tyroler HA, Comstock GW, Shahar E, et al. Neighborhood environments and coronary heart disease: a multilevel analysis. Am J Epidemiol (1997) 146(1):48-63. doi:10.1093/oxfordjournals.aje. a009191

44. Barr RG, Diez-Roux AV, Knirsch CA, Pablos-Mendez A. Neighborhood poverty and the resurgence of tuberculosis in New York City, 1984-1992. Am J Public Health (2001) 91(9):1487-93. doi:10.2105/AJPH.91.9.1487

45. King-Shier KM, Mather C, LeBlanc P. Understanding the influence of urbanor rural-living on cardiac patients' decisions about diet and physical activity: descriptive decision modeling. Int J Nurs Stud (2013) 50(11):1513-23. doi:10.1016/j.ijnurstu.2013.03.003

46. Kullgren JT, McLaughlin CG, Mitra N, Armstrong K. Nonfinancial barriers and access to care for U.S. adults. Health Serv Res (2012) 47(1 Pt 2):462-85. doi:10.1111/j.1475-6773.2011.01308.x

47. Sudano JJ, Baker DW. Explaining US racial/ethnic disparities in health declines and mortality in late middle age: the roles of socioeconomic status, health behaviors, and health insurance. Soc Sci Med (2006) 62(4):909-22. doi:10.1016/ j.socscimed.2005.06.041

48. Murchie P, Raja EA, Brewster DH, Campbell NC, Ritchie LD, Robertson R, et al. Time from first presentation in primary care to treatment of symptomatic colorectal cancer: effect on disease stage and survival. Br J Cancer (2014) 111(3):461-9. doi:10.1038/bjc.2014.352

49. Vandborg MP, Christensen RD, Kragstrup J, Edwards K, Vedsted P, Hansen DG, et al. Reasons for diagnostic delay in gynecological malignancies. Int J Gynecol Cancer (2011) 21(6):967-74. doi:10.1097/IGC.0b013e31821d2770

50. Schulz AJ, Israel BA, Zenk SN, Parker EA, Lichtenstein R, Shellman-Weir $\mathrm{S}$, et al. Psychosocial stress and social support as mediators of relationships between income, length of residence and depressive symptoms among African American women on Detroit's eastside. Soc Sci Med (2006) 62(2):510-22. doi:10.1016/j.socscimed.2005.06.028

51. Ross CE, Mirowsky J. Neighborhood disorder, subjective alienation, and distress. J Health Soc Behav (2009) 50(1):49-64. doi:10.1177/002214650905000104

52. Augustin T, Glass TA, James BD, Schwartz BS. Neighborhood psychosocial hazards and cardiovascular disease: the Baltimore memory study. Am J Public Health (2008) 98(9):1664-70. doi:10.2105/AJPH.2007.125138

53. Ross CE, Mirowsky J. Neighborhood disadvantage, disorder, and health. J Health Soc Behav (2001) 42(3):258-76. doi:10.2307/3090214

54. Ben-Eliyahu S, Page GG, Schleifer SJ. Stress, NK cells, and cancer: still a promissory note. Brain Behav Immun (2007) 21(7):881-7. doi:10.1016/j.bbi. 2007.06.008

55. Clegg LX, Reichman ME, Miller BA, Hankey BF, Singh GK, Lin YD, et al. Impact of socioeconomic status on cancer incidence and stage at diagnosis: selected findings from the surveillance, epidemiology, and end results: National 
Longitudinal Mortality Study. Cancer Causes Control (2009) 20(4):417-35. doi:10.1007/s10552-008-9256-0

56. Lutgendorf SK, Sood AK, Anderson B, McGinn S, Maiseri H, Dao M, et al. Social support, psychological distress, and natural killer cell activity in ovarian cancer. J Clin Oncol (2005) 23(28):7105-13. doi:10.1200/JCO.2005.10.015

57. Browning CR, Feinberg SL, Wallace D, Cagney KA. Neighborhood social processes, physical conditions, and disaster-related mortality. Am Sociol Rev (2006) 71(4):661-78. doi:10.1177/000312240607100407

58. Joslin CE, Brewer KC, Davis FG, Hoskins K, Peterson CE, Pauls HA. The effect of neighborhood-level socioeconomic status on racial differences in ovarian cancer treatment in a population-based analysis in Chicago. Gynecol Oncol (2014) 135:285-91. doi:10.1016/j.ygyno.2014.08.029

59. Parham G, Phillips JL, Hicks ML, Andrews N, Jones WB, Shingleton HM, et al. The national cancer data base report on malignant epithelial ovarian carcinoma in African-American women. Cancer (1997) 80(4):816-26. doi:10.1002/(SICI) 1097-0142(19970815)80:4<816::AID-CNCR21>3.0.CO;2-V

60. O'Malley CD, Shema SJ, Cress RD, Bauer K, Kahn AR, Schymura MJ, et al. The implications of age and comorbidity on survival following epithelial ovarian cancer: summary and results from a Centers for Disease Control and Prevention study. J Womens Health (Larchmt) (2012) 21(9):887-94. doi:10.1089/jwh. 2012.3781

61. Krieger N, Chen JT, Waterman PD, Soobader MJ, Subramanian SV, Carson R. Geocoding and monitoring of US socioeconomic inequalities in mortality and cancer incidence: does the choice of area-based measure and geographic level matter?: the Public Health Disparities Geocoding Project. Am J Epidemiol (2002) 156(5):471-82. doi:10.1093/aje/kwf068

Conflict of Interest Statement: The authors declare that the research was conducted in the absence of any commercial or financial relationships that could be construed as a potential conflict of interest.

Received: 11 November 2014; accepted: 06 January 2015; published online: 22 January 2015.

Citation: Peterson CE, Rauscher GH, Johnson TP, Kirschner CV, Freels S, Barrett RE, Kim S, Fitzgibbon ML, Joslin CE and Davis FG (2015) The effect of neighborhood disadvantage on the racial disparity in ovarian cancer-specific survival in a large hospital-based study in Cook County, Illinois. Front. Public Health 3:8. doi: 10.3389/fpubh.2015.00008

This article was submitted to Epidemiology, a section of the journal Frontiers in Public Health.

Copyright $\odot 2015$ Peterson, Rauscher, Johnson, Kirschner, Freels, Barrett, Kim, Fitzgibbon, Joslin and Davis. This is an open-access article distributed under the terms of the Creative Commons Attribution License (CC BY). The use, distribution or reproduction in other forums is permitted, provided the original author(s) or licensor are credited and that the original publication in this journal is cited, in accordance with accepted academic practice. No use, distribution or reproduction is permitted which does not comply with these terms. 